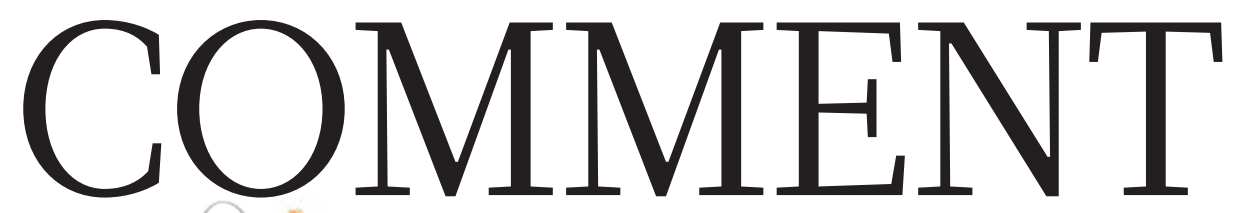

HISTORY LesSons from the first large-scale environmental assessments p.310
FICTION Thomas

Pynchon's latest novel p.312
ECONOMIES Comparing accounts of innovation in Russia and the United States p.313
MATHEMATICS Martin Gardner's posthumously published autobiography $\mathbf{p . 3 1 4}$

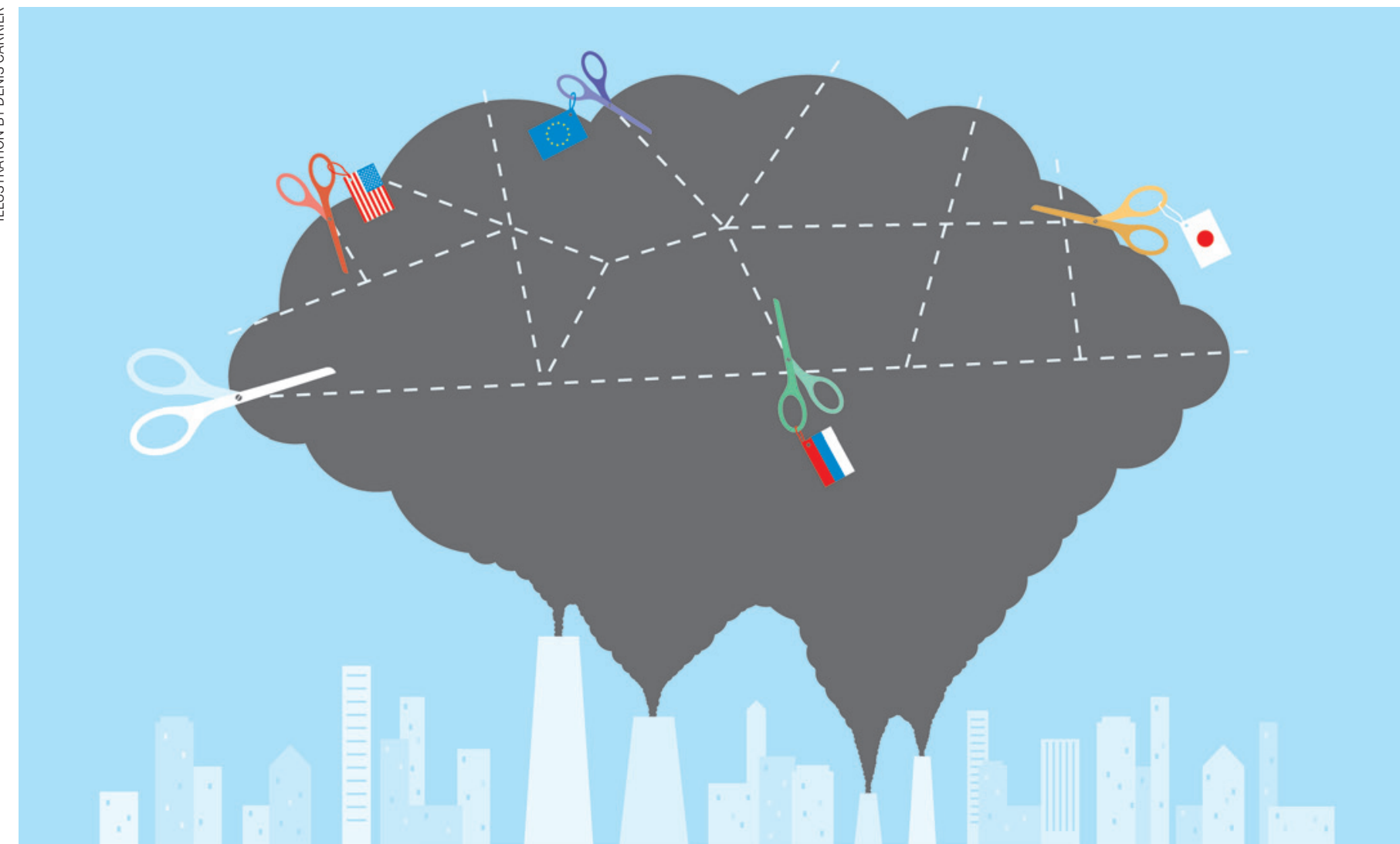

\title{
A patchwork of emissions cuts
}

\section{Home-made national approaches can be effective for climate-change mitigation if countries agree on rules and build trust, says Elliot Diringer.}

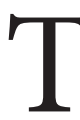

he last thing that most people recall about United Nations climate-change talks was the meltdown four years ago in Copenhagen, when presidents and prime ministers at the 15 th Conference of the Parties (COP) to the UN Framework Convention on Climate Change (UNFCCC) failed to deliver the strong, binding treaty that the world had been led to expect.

Negotiations have, in fact, continued, and governments have set another deadline: a new global climate agreement in 2015 . With this latest round of talks nearing its midpoint, hints of a way forward are beginning to emerge. The path that they suggest

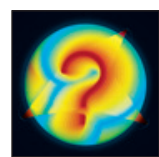

\section{OUTLOOKFOR EARTH}

A Nature special issue on the IPCC nature.com/ipcc2013 is at once encouraging and underwhelming.

Governments are yet to formally agree on anything. But in discussions earlier this year in Bonn, Germany, they began earnestly exploring a middle way - one neither as rigorous as the fading Kyoto Protocol to the UNFCCC, nor simply do-as-you-please. Although this approach might not look much like a grand climate solution, it is one that over time could substantially 
advance the global climate effort.

In the emerging model, which has been advanced by the United States among others, the efforts of countries would be tracked under agreed rules. But individual emissionsreduction goals would be set by each country on its own, without negotiation. The agreement would, in essence, stitch together a mixture of self-defined contributions. To encourage ambition, countries would scrutinize each other's initial offerings.

Having learned hard lessons in Copenhagen, governments are tempering their expectations this time around. Many now seem willing to accept a looser pact, if it can get everyone on board and offer the promise of strengthening action over time.

This thinking reflects in part the stubborn political reality that, despite the rising toll of extreme weather and other climate impacts, governments remain much more preoccupied with flagging economies than with climate disruption. It also reflects a sober reassessment of what the UNFCCC can effectively deliver. It is a concession to the limits of global diplomacy and law in tackling this truly global challenge, and a recognition that, whatever the UNFCCC's role is in moving forward, much of the real work to stave off climate catastrophe must happen at home.

\section{TWISTS AND TURNS}

An early test for the emerging approach could come at COP19 this November in Warsaw. Some nations are likely to push for a formal process to begin eliciting and assessing countries' intended commitments. If the talks stay true to past form, however, definitive outcomes on the structure of an agreement, let alone the content, are unlikely to arise until the closing hours of COP21 in 2015.

This point in the UNFCCC's evolution may be understood by looking back to the framework's negotiation two decades ago. Competing governance models that dominated the debate then remain a source of tension. One model is the 'top-down' approach: countries agree on a long-term climate goal and a formula for allocating legally binding emissionsreduction targets that are stringent enough to achieve it. The other is a 'bottom-up' policy: countries offer up whatever commitments they like on a voluntary basis.

Elements of both models found their way into the UNFCCC, the parent agreement that has been ratified by 195 parties, under which the negotiations have proceeded since it entered into force in 1994. Parties leaned towards a top-down approach for the 1997 Kyoto Protocol, which set binding emissions targets for developed countries only, with the target levels negotiated rather than simply asserted.

Legally and technically, Kyoto introduced greater rigour into global climate governance. Politically, it has proven unsound. The
United States never ratified the protocol; Canada did, but later withdrew; and Japan and Russia refused to sign on for a second round of obligations. The current (and probably final) Kyoto targets, which run until 2020 , cover only Europe and a handful of other countries - totalling less than $15 \%$ of global emissions. In the meantime, parties have spun together a parallel framework that takes a bottom-up approach. Copenhagen did produce a political accord that was formalized a year later in the Cancun Agreements, inviting voluntary emission pledges to be achieved by 2020 .

More than 90 countries representing some $80 \%$ of global emissions - including, for the first time, all the world's major economies - submitted pledges under the agreements. But they are too weak to put the world on a pathway to keep warming below $2{ }^{\circ} \mathrm{C}$ above pre-industrialized levels. The UN Environment Programme projects that, even in the best case, the pledges will achieve less than half of the reductions needed by 2020 .

So governments have now experimented with both top-down and bottom-up approaches, and neither is getting the job done. Kyoto lacks adherents; the Cancun Agreements lack ambition. Is it possible to forge a middle path that has some chance of delivering both?

In launching the latest round of talks, parties agreed on little beyond a deadline (2015) and a start date for an agreement (2020). The mandate "Kyotolacks for the talks, part of a adherents; the Cancun package deal struck Agreements lack ambition." at COP17 in 2011 in Durban, South Africa, requires "a protocol, another legal instrument or an agreed outcome with legal force under the Convention applicable to all Parties". An exemplar of constructive ambiguity, this hard-fought phrase manages to address, while leaving entirely unresolved, two perennial issues: legal form and the distribution of effort between developed and developing countries.

Since Durban, developing countries have continued to insist that wealthy nations bear a much greater responsibility for reducing emissions because, both cumulatively and per capita, they have generated so many more. Developed countries are equally adamant that the mandate ends the strict binary approach of the Kyoto Protocol: binding emissions targets for developed countries, and no commitments for developing countries.

The distinction between developed and developing countries would be less important in the type of agreement visualized by the United States. All countries' obligations would have the same legal character - if they are binding for some, then they are binding for all. But beyond that, countries would have wide latitude in deciding the stringency and type of their emissions-reduction measures. The United States proposed in March that parties should "define their own mitigation contributions, taking into account national circumstances, capacity, and other factors that they consider relevant".

Most other parties seem willing to accept that the stringency of future commitments will be self-defined. But developing countries continue to call for differentiation in type, with developed countries adopting economy-wide emissions-reduction targets, and developing countries free to pursue other measures, as in the Cancun Agreements.

\section{BUILDING AMBITION}

The major issue that negotiators are struggling with, however, is how to build ambition into the model, and how to ensure that collective action does reduce global emissions overall. Much of the thinking so far has centred on some form of 'ex-ante' review of commitments. If countries submit their intended offerings to scrutiny before they are formally inscribed, they might be more ambitious. A similar approach has been used for many years in the global trade regime to progressively reduce tariffs.

In the US view, the review would simply involve governments exchanging proposals and responses bilaterally. The European Union (EU) and others foresee a more open, formal process. In May, the EU outlined a 'stepwise approach' that would begin by spelling out the information needed from parties to ensure that their proposals are "transparent, quantifiable and comparable", and lead to a "collective consideration of [their] overall adequacy.... and the increase of ambition if needed to stay on track for below $2{ }^{\circ} \mathrm{C}$ ".

Many parties also want a 'ratcheting' mechanism to boost ambition over time. Instead of a lengthy process of negotiation and ratification for each set of commitments, they foresee a dynamic, evolving agreement. Countries would report on how they are implementing their existing commitments, assess one another's efforts and then initiate another round of offers and reviews - a continuous cycle inducing a progressively stronger, collective effort.

If successful, such an arrangement could have an additive effect. Still, its fundamental force would derive less from the rule of international law than from the concrete national programmes that it would presumably stitch together. The most important quotient would remain domestic political will.

There are encouraging signs: China is pushing forward with carbon trading, and US President Barack Obama has promised to cut carbon emissions from US power plants. But at the same time, Germany and the United Kingdom are burning more coal, China's emissions continue to soar 

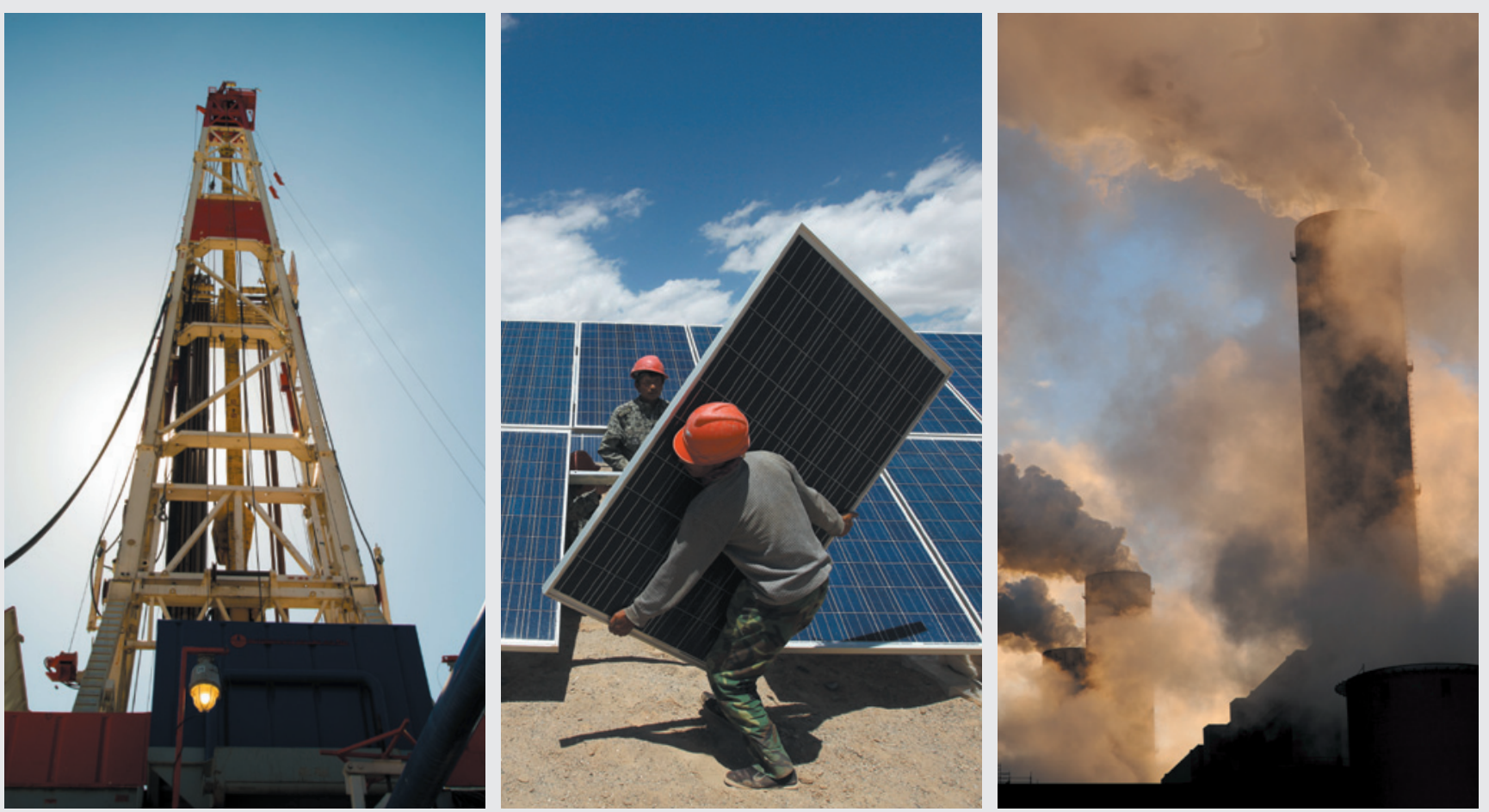

Gas drilling in Pennsylvania; solar-panel installation in Jiuquan, China; a coal plant in Grevenbroich, Germany's 'energy capital'.

\section{CASE STUDIES}

\section{Leading emitters}

United States. Emissions are down from their 2007 peak, largely as a result of a slow economy, a natural-gas boom and advances in energy efficiency. Declaring climate change a top priority for his second term, President Barack Obama is promising to use his executive powers to reduce emissions further. Obama's directive to the US Environmental Protection Agency to regulate carbon from power plants could put the country in a position to meet the president's 2009 pledge at the Copenhagen climate summit of a $17 \%$ cut (from 2005 levels) by 2020 . There remains little prospect of the politically fractured US Congress enacting anything more ambitious.
China. The country is forging ahead with the very market-based approach to cutting carbon that the US Congress rejected. Having seized a major share of the global renewabletechnology market (upsetting US and European Union (EU) trade), China is piloting eight regional 'cap-and-trade' systems, with the goal of a national carbon market by 2020 .

Yet China's dependence on high-carbon energy shows few signs of abating. The International Energy Agency in Paris projects that China's coal and oil consumption will rise by $23 \%$ and $46 \%$, respectively, by 2020 - when its carbon dioxide emissions will have exceeded those of the United States and EU combined.

Copenhagen. But whether or not anything firm is agreed in November, the parties will face mounting pressure to put preliminary targets on the table by the time UN secretarygeneral Ban Ki-moon gathers leaders for a climate summit in September 2014.

In the subsequent year, they will also need to decide how a new pact would address a host of other issues, such as helping poor countries to cope with climate impacts, the role of carbon markets and the agreement's legal force. Will countries' self-defined commitments be legally binding? Or perhaps only the periodic reporting of what they have achieved?
Europe. It has long been the most climatecommitted of the three leading emitters, but rolling economic crises have weakened climate fervour. A push to strengthen the EU's 2020 emissions target (from 20\% to $30 \%$ below 1990 levels) has been sidetracked by the recession.

Although sluggish economies in eastern Europe have kept overall emissions from the continent falling, coal use and emissions are edging up in Germany and the United Kingdom. Even as Germany invests heavily in renewable power, it is importing record levels of coal - a result of nuclear shutdowns following the 2011 Fukushima disaster in Japan and rising natural-gas prices. and carbon pricing remains off the table in Washington DC (see 'Leading emitters')

odds of reaching an agreement Climate Change scheduled to begin the staggered release of its Fifth Assessment Report next week, and costly climate impacts growing steadily, governments know that they must produce something. And they seem to be further along in understanding what that might be than they were last time.

The French government, which is slated to host the 2015 talks, is moderating expectations in the hope of avoiding a repeat of hagen. With the Intergovernmenta Panelon
A new agreement will probably not be heroic, but it can be pragmatic. With creativity and compromise, governments can devise a multilateral framework that lends coherence, transparency and rigour to the emerging patchwork of national efforts. That, in turn, can strengthen countries' confidence in one another, in the process and in our collective ability to overcome the climate challenge.

Elliot Diringer is executive vice-president of the Center for Climate and Energy e-mail:diringere@c2es.org Solutions (C2ES) in Arlington, Virginia. 